\title{
Feasibility of whole body vibration during intensive chemotherapy in patients with hematological malignancies - a randomized controlled pilot study
}

\author{
Antonia Pahl ${ }^{1 *}$ (D, Anja Wehrle², Sarah Kneis ${ }^{1}$, Albert Gollhofer ${ }^{3}$ and Hartmut Bertz ${ }^{1}$
}

\begin{abstract}
Background: Hospitalized cancer patients undergoing intensive or high-dose chemotherapy often experience a considerable decline in functional performance associated with the increased risk of adverse health events. Exercises, particularly resistance-based exercises that may counteract this decline are restricted by therapy-related side effects. Since whole body vibration (WBV) is known to efficiently stimulate the neuromuscular system without significantly raising blood pressure, we hypothesize that especially WBV is particularly feasible even during intensive or high-dose chemotherapy (primary endpoint) and thus induces beneficial functional adaptations.
\end{abstract}

Methods: Twenty hospitalized patients with hematological malignancies scheduled for intensive or high-dose chemotherapy were randomly allocated to an intervention group $(I G)$ undergoing WBV, or an active control group (CG) cycling. Feasibility was determined by comparing the IG's and CG's training compliance. Furthermore, to assess feasibility, WBV-induced changes in chemotherapy-related side effects, blood pressure, and heart rate immediately after exercising were documented. To assess patients' functional performance, we measured jump height (cm), the duration (sec) of performing the chair rising- (CRT) and timed-up-and-go test (TUG), maximum power output during jumping and CRT (watt/kg) as well as sway path $(\mathrm{mm})$ during balance tasks.

Results: Training compliance was similar between groups (IG: median 62\%, range 39-77; CG: 67\%, 58-100; $p=0.315$ ). Moreover, we observed neither the IG's reported side effects worsening, nor any increase in blood pressure after WBV. IG's jump height $(+2.3 \mathrm{~cm}, 95 \% \mathrm{Cl} 0.1-4.4, p=0.028)$ and TUG performance $(-1.3 \mathrm{~s}, 95 \% \mathrm{Cl}-2.53--0.65, p=0.027)$ improved significantly, while sway paths in semi-tandem stance were augmented after the intervention (eyes open: + $60 \mathrm{~mm}, 95 \% \mathrm{Cl} 2-236, p=0.046$; eyes closed: $+88 \mathrm{~mm}, 95 \% \mathrm{Cl}$ 49-214, $p=0.028)$. The CG's performances did not change over time. Maximum power output during CMJ and CRT and time during CRT did not change.

Conclusion: Our study is the first proving the feasibility of WBV during intensive/high-dose chemotherapy of hospitalized cancer patients. Additionally, WBV-induced neuromuscular adaptations resulted in functional benefits relevant to patients' autonomy. We believe that WBV can be implemented as an alternative training method during intensive chemotherapy, although the relative benefit compared to conventional resistance training requires more evaluation in future studies.

Trial registration: German Register of Clinical Trials No.: DRKS00004338, prospectively registered on 11/30/2012.

Keywords: Exercise therapy, Postural balance, Cancer therapy, Acute leukemia, Bone marrow neoplasm, Intervention study, Activities of daily living

\footnotetext{
* Correspondence: antonia.pah|@uniklinik-freiburg.de

'Department of Medicine I (Specialties: Hematology, Oncology, and

Stem-Cell Transplantation), Faculty of Medicine, Medical Center - University

of Freiburg, Hugstetterstr. 55, 79106 Freiburg, Germany

Full list of author information is available at the end of the article
}

(c) The Author(s). 2018 Open Access This article is distributed under the terms of the Creative Commons Attribution 4.0 International License (http://creativecommons.org/licenses/by/4.0/), which permits unrestricted use, distribution, and reproduction in any medium, provided you give appropriate credit to the original author(s) and the source, provide a link to the Creative Commons license, and indicate if changes were made. The Creative Commons Public Domain Dedication waiver (http://creativecommons.org/publicdomain/zero/1.0/) applies to the data made available in this article, unless otherwise stated. 


\section{Background}

Many patients diagnosed with hematologic malignancies (e.g. leukemia) undergo intensive or high-dose chemotherapy $[1,2]$ leading to cytopenia and other side effects $[3,4]$. These are manifold and can impair physical and psychological functioning considerably. Because of the growing risk of complications due to aplasia (e.g. infections, bleeding), patients are usually hospitalized for two to 4 weeks, meaning a period of restricted mobility associated inter alia with muscle-mass loss, and reduced strength capacity and functional performance $[5,6]$. It is common knowledge that impaired functional performance and poor body composition, i.e. disproportionally less muscle mass, limit patients' autonomy and quality of life $[7,8]$ and may raise the mortality risk [9-11]. All cancer patients are therefore recommended to be physically active during treatment while considering specific limitations to counteract physical deconditioning and preserve mobility [12-14]. There is evidence that exercising (e.g. aerobic exercises, especially cycling) even during high-dose chemotherapy (as conditioning therapy prior to allogeneic hematopoietic cell transplantation) is safe and effective, and has the potential to reduce physical and psychosocial side effects [13, 15-19]. However, aerobic exercises alone appear insufficient to affect functional impairments especially, whereas some studies added resistance training to their intervention program [19-21]. They confirmed the feasibility of resistance training during chemotherapy and demonstrated positive effects on patients' physical functioning, but could not entirely maintain muscle strength during hospitalization. Taking into account catabolic medication [22, 23] and the amount of time patients are exposed to bed rest, high intensities and volumes of resistance training were needed to significantly avoid losing strength [24] and its functional consequences, factors that are relevant prognostic factors for survival [11]. However, according to current recommendations [14, 25] patients' blood values, i.e. platelets counts, and well-being may limit the intensity and volume of resistance training patients are able to perform during intensive chemotherapy.

We therefore planned to introduce whole body vibration (WBV) as a resistance training method for patients undergoing intensive chemotherapy during hospital stay. WBV induces frequency-dependent repeating contractions of the muscles culminating in a tonic vibration reflex that enhances the recruitment of motor units [26, 27]. WBV thus reveals EMG activity similar to that during conventional squat exercises with external loads [28]. It thus stimulates the musculoskeletal system very time-efficiently and can improve muscle strength [29] and functional performance [30]. Furthermore, it evidently prevents muscle-mass loss during bed rest [6, 31]. With all these effects, WBV has little impact on vital parameters, e. g. blood pressure [32, 33]. We therefore believe that WBV is feasible even for patients during thrombocytopenia. Additionally, it might be less tiring and easier to carry out, but similarly effective to resistance training because of the high neuromuscular activity even under passive conditions when following current recommendations [14]. Up to now, results of WBV's feasibility or effectiveness are only available to cancer patients after active anti-cancer treatment [34-36]. There is only one ongoing study [37] investigating WBV during chemotherapy, but no results have yet been published. We thus implemented a randomized controlled pilot study to assess primarily the feasibility of WBV during intensive and high-dose chemotherapy during hospital stay. Since aerobic exercise has proven to be safe and feasible for hospitalized patients during high-dose chemotherapy $[16,38]$ we aimed to compare exercise's feasibility of WBV versus an active control group performing aerobic cycling exercises. Secondarily, we attempted to evaluate WBV-induced effects on patient's functional performance. We hypothesized that patients would adhere to the WBV exercise sessions as prescribed despite therapy-related side effects without exhibiting differences from the control group. Furthermore, WBV might induce neuromuscular adaptations leading to functional benefits.

\section{Methods \\ Study design and patients}

The main objective of this randomized controlled pilot study was to confirm WBV's feasibility in hospitalized patients with hematological malignancies undergoing intensive or high dose chemotherapy. Patients were recruited at the Department of Medicine I, University Medical Center Freiburg, Germany, immediately after hospital admission. Within a 7-month time frame, eligible patients were randomly allocated to either an intervention group (IG) or active control group (CG). Block randomization was based on a computer-assisted pseudo-random number generator (Research Randomizer, Version 4.0). Inclusion criteria were diagnosis of a hematological malignancy, scheduled for intensive/ high-dose chemotherapy with a two- to four-week period of hospitalization, and written informed consent. Absolute exclusion criteria were any unstable bone metastasis, a knee or hip endoprosthesis, epilepsy, pacemaker, severe cardiovascular diseases [36, 39] and threshold blood-count values below safety criteria (platelets count $\leq 10.000 / \mu \mathrm{l}$ and hemoglobin $\leq 8 \mathrm{~g} / \mathrm{dl}$ ) $[40,41]$. Relative exclusion criteria included stents or former joint injuries. Baseline parameters were assessed before the first administration of chemotherapy (T0) and post-evaluated immediately before discharge (T1), respectively. Table 1 summarizes patients' clinical information. The study was 
Table 1 Clinical information of completer $(n=11)$ and all randomized patients ( $n=20$, completer and drop-outs)

\begin{tabular}{|c|c|c|c|}
\hline & \multicolumn{2}{|l|}{ Completer } & \multirow{2}{*}{$\begin{array}{l}\text { All } \\
n=20\end{array}$} \\
\hline & $\begin{array}{l}\mathrm{IG} \\
n=6\end{array}$ & $\begin{array}{l}\mathrm{CG} \\
n=5\end{array}$ & \\
\hline$\overline{\text { Age [years] }}{ }^{a}$ & $47(19-62)$ & $56(32-63)$ & $55(47-63)$ \\
\hline Sex [n] male:female & $5: 1$ & $3: 2$ & $14: 6$ \\
\hline BMI $\left[\mathrm{kg} / \mathrm{m}^{2}\right]^{\mathrm{a}}$ & $26(20-28)$ & $26(22-28)$ & $26(25-27)$ \\
\hline \multicolumn{4}{|l|}{ Diagnosis [n] } \\
\hline AML & 1 & 4 & 8 \\
\hline ALL & 1 & 0 & 1 \\
\hline APL & 1 & 0 & 1 \\
\hline $\mathrm{NHL}$ & 2 & 0 & 5 \\
\hline $\mathrm{HL}$ & 0 & 0 & 1 \\
\hline t-cell lymphoma & 1 & 0 & 1 \\
\hline MW & 0 & 0 & 1 \\
\hline MM & 0 & 1 & 1 \\
\hline PMF & 0 & 0 & 1 \\
\hline \multicolumn{4}{|l|}{ Remission [n] } \\
\hline ED & 1 & 3 & 7 \\
\hline SD & 0 & 1 & 2 \\
\hline PD & 1 & 0 & 1 \\
\hline$C R$ & 0 & 1 & 2 \\
\hline PR & 0 & 0 & 1 \\
\hline recurrence & 2 & 0 & 5 \\
\hline N/A & 2 & 0 & 2 \\
\hline Time since initial diagnosis [weeks] $]^{a}$ & $46(2-371)$ & $6(2-215)$ & $32(7-128)$ \\
\hline Cycles of chemotherapy before admission $[n]^{a}$ & $9(0-16)$ & $1(0-9)$ & $4(1-9)$ \\
\hline \multicolumn{4}{|l|}{ Type of chemotherapy during intervention [n] } \\
\hline High-dose prior to autologous HSCT & 1 & 1 & 5 \\
\hline Induction therapy for AML & 4 & 3 & 8 \\
\hline Intensive chemotherapy for ALL, HL, NHL & 1 & 1 & 7 \\
\hline Duration of hospitalization [days] ${ }^{\mathrm{a}}$ & $27(21-56)$ & $27(16-69)$ & $26(22-34)$ \\
\hline Karnofsky performance index [\%] ${ }^{a}$ & $95(80-100)$ & $90(80-100)$ & $90(85-90)$ \\
\hline
\end{tabular}

${ }^{a}$ Median (range), $B M I$ body mass index, $A M L$ acute myeloid leukemia, $A L L$ acute lymphocytic leukemia, $A P L$ acute promyelocytic leukemia, $N H L$ non-Hodgkin lymphoma, $H L$ Hodgkin lymphoma, $M W$ morbus Waldenström, $M M$ multiple myeloma, $P M F$ primary myelofibrosis, $E D$ initial diagnosis, $S D$ stable disease, $P D$ progress disease, $C R$ complete remission, $P R$ partial remission, HSCT hematopoietic cell transplantation

approved by the Ethics Committee of the University of Freiburg and conducted according to the Declaration of Helsinki (German Register of Clinical Trials No.: DRKS00004338).

\section{Intervention}

Both groups' one-on-one training sessions took place in a separate room on the patients ward during three sessions per week, each lasting $20 \mathrm{~min}$.

The IG's exercise protocol included three sets of two to four different exercises (static and dynamic squats, heel raise and combination of both) on the Galileo ${ }^{\circ}$ Sport vibration platform (Novotec Medical $\mathrm{GmbH}$,
Pforzheim, Germany) which is adjustable in steps of $0.5 \mathrm{~Hz}$ within a range of $5-30 \mathrm{~Hz}$. Each exercise lasted 30 to 60 s depending on patients' condition with a 30 to $60 \mathrm{~s}$ rest between exercises and 60 to $120 \mathrm{~s}$ between sets. Patients should reach intensity prescription of 14 to 16 on the perceived exertion rating scale (Borg 6-20) [40, 42]. To generate the best neuromuscular response, exercises were performed within a frequency range of $18-25 \mathrm{~Hz}$ and at 3.5-4 mm amplitude [43, 44]. During static exercises, patients were asked to shift their body weight on their forefeet and to maintain a knee angle of approx. Sixty degrees flexion in static position [43]. If patients couldn't maintain the forefoot position 
throughout the exercise period, we supported their stance position via a heel foam wedge.

The CG performed aerobic exercises on a bicycle ergometer. Exercise sessions also lasted up to $20 \mathrm{~min}$ with the same intensity prescription as the IG. For patients unable to endure 20 min continuous cycling, an individual interval program with periods of rest was used to achieve 20 min cycling in total for each exercise session.

We consulted patients' files for blood values before each exercise session to ensure their values met our safety criteria: platelets count $\geq 10.000 / \mu \mathrm{l}$ and hemoglobin $\geq 8 \mathrm{~g} / \mathrm{dl}$. Additionally, we controlled patients' blood pressure and heart rate before and after each exercise session to avoid overload. Blood values, blood pressure, training progress and reasons for missed sessions were documented.

\section{Outcome measures}

\section{Primary endpoint feasibility}

We determined the feasibility of WBV by comparing the IG's and CG's training compliance. Training compliance in percent was calculated as completed exercise sessions divided by planned exercise sessions.

Furthermore, exercise-related adverse events were documented and reasons for missed exercise sessions were compared between groups. The tolerability of vibration training was also assessed via a self-designed questionnaire that asked (a) for the extent of chemotherapy-induced side effects (concerning pain, illness, dizziness, etc.) immediately before and after each vibration training session to examine whether WBV might enhance or weaken these side effects and (b) to determine their WBV-induced well-being. This questionnaire included 18 items scored from 0 to 3 (not at all, marginally, quite a lot, very much). Additionally, blood pressure and heart rate were measured and documented immediately before and after exercising as well as at the two measurement sessions (T0 and T1).

\section{Secondary endpoint functional performance}

All functional performance measurements were taken on a force plate (Leonardo Mechanograph ${ }^{\circledR}$ GRFP, Novotec Medical GmbH, Pforzheim, Germany) that determined dynamic ground reaction forces in its local and temporal progress. Data were recorded with a sample rate of $800 \mathrm{~Hz}$ and analyzed using Leonardo Mechanograph ${ }^{\circ}$ Research-Software (Novotec Medical GmbH, Pforzheim, Germany).

To test functional performance under dynamic conditions, two common functional tasks were performed: a maximum counter-movement jump (CMJ) and a chair-rising test (CRT). Both tests evaluate leg muscle power output which in turn reflects the efficiency of lower limb neuromuscular interaction [45]. Patients executed CMJ with freely-moving arms and were instructed to jump as high as possible. Outcomes were defined as maximum power output during take-off per kilogram body weight $\left(\mathrm{P}_{\text {max } \_ \text {CMJ; }} \mathrm{W} / \mathrm{kg}\right)$ and jumping height $(\mathrm{cm})$. For CRT, patients started in a sitting position with their arms crossed over their chest. Patients had to stand up from a bench $(45 \mathrm{~cm}$, Novotec Medical $\mathrm{GmbH})$ and sit down again five times in a row. They were asked to rise up until full extension of the knee and hip and to sit down using their full bodyweight. Durations (sec) of the second, third and fourth repetition were recorded and the average duration was calculated of one repetition [46]. Additionally, power output during stand up $\left(\mathrm{P}_{\max \_C R T ;} \mathrm{W} / \mathrm{kg}\right)$ was measured for the CRT. Best values out of two trials per test condition were used to analyze CMJ and CRT.

Functional performance under static conditions was evaluated by changes in balance performance, known to indicate neuromuscular and functional impairments [47, 48]. We determined the center of force (COF) displacement in anterio-posterior and medio-lateral direction during three different stance conditions: semi-tandem stance with eyes open (EO) and eyes closed (EC) and one-leg stance in EO condition. Assessments took place without shoes. Patients were asked to stand upright and comfortably and direct their gaze onto a marked spot located at eye level on the wall. Sway path $(\mathrm{mm})$ and standard ellipse $\left(\mathrm{cm}^{2}\right)$ of COF was recorded over a period of 30s. The mean value out of three trials was used for analysis.

\section{Secondary endpoint mobility}

To assess basic functional mobility in a daily situation, we used the timed-up-and-go test (TUG) commonly used to evaluate patients' autonomy in daily life [49]. Duration (sec) was recorded from the moment patients got up from an armed chair, walked three meters, turned around, walked back and sat down on the chair again $[49,50]$.

\section{Statistics}

All variables were included in non-parametric analysis as the assumption of normal distribution (Shapiro-Wilk test) was not satisfied and the sample size is small. Differences in training compliance between both groups and differences of groups' delta (T1-T0) were assessed by Mann-Whitney-U-test. Intragroup differences over time were computed by Wilcoxon signed-rank test. The level of significance was set to $p<0.05$. Group data are presented as median and 95\% confidence interval (95\% $\mathrm{CI})$. To estimate the treatment effect the point estimate and 95\% confidence interval of the Hodges-Lehmann's median differences for paired groups were used. All statistical analyses were conducted using IBM SPSS Version 22 software (SPSS Inc., Chicago, Illinois, USA). 


\section{Results}

No adverse events were observed during the study period. No baseline assessment was possible in three CG patients. Thus 17 patients participated in our intervention program and were included in the feasibility analysis. However, no post-intervention data on two CG and four IG patients were available (Fig. 1). Eleven patients were thus ultimately included in our functional performance and mobility analyses.

\section{Feasibility}

No adverse events or differences in groups' training compliance were observed during any of the WBV training sessions (IG: 62\%, CG: 67\%, $p=0.315$ ) (Table 2 and Fig. 2a). Reasons for missed exercise sessions were similar between groups (Table 2) and no training session had to be cancelled due the type of exercise. Furthermore, WBV training did not worsen subjective chemotherapy-induced side effects: -0.02 (a difference of 0 would represent no

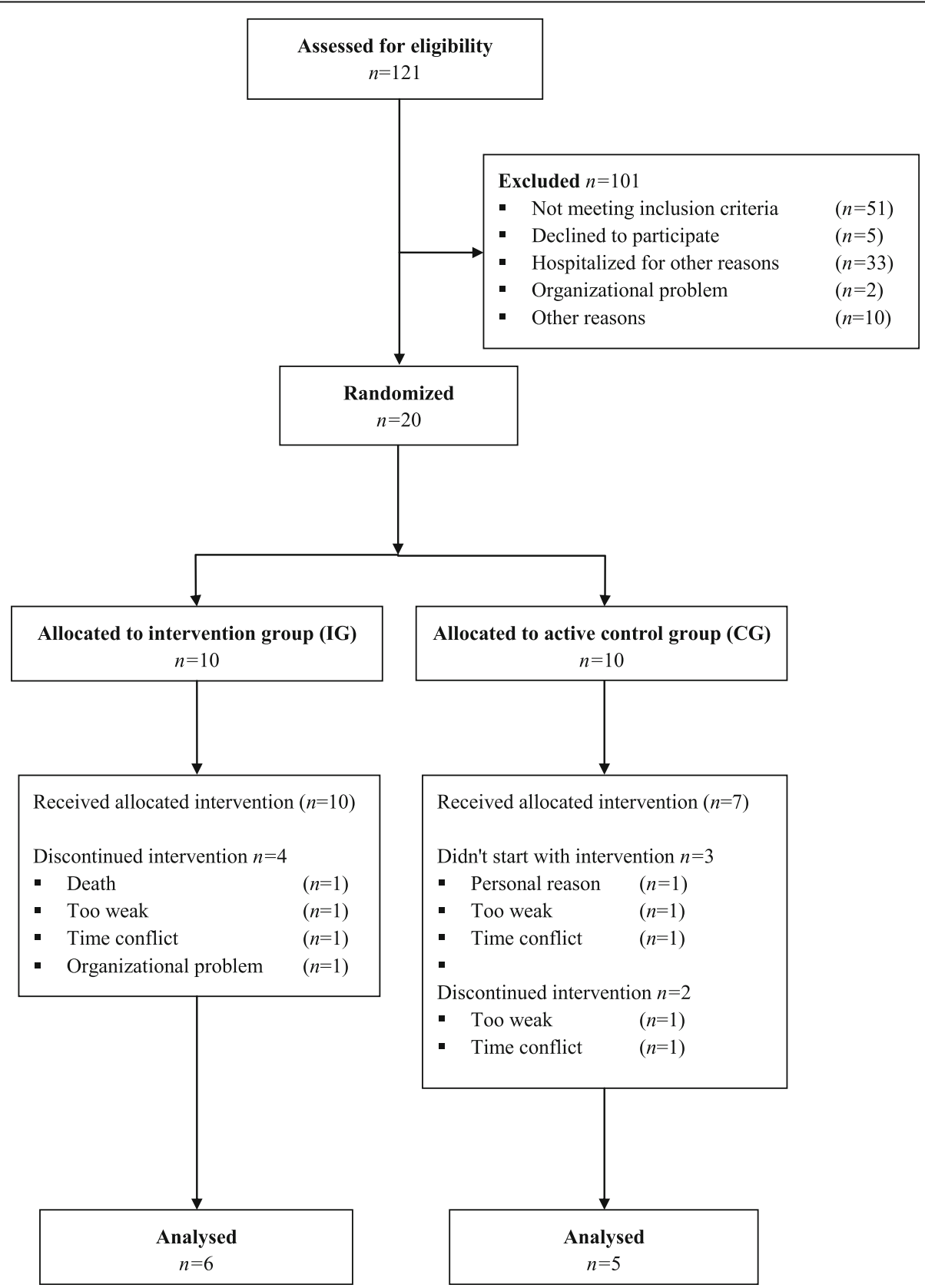

Fig. 1 Flow diagram of study recruitment 
Table 2 Comparison of groups' training compliance and reasons for missed exercise session for all patients participating in the training program $(n=17)$

\begin{tabular}{|c|c|c|c|}
\hline & $\begin{array}{l}\mathrm{IG} \\
n=10\end{array}$ & $\begin{array}{l}C G \\
n=7\end{array}$ & $P$ \\
\hline Compliance $[\%]^{a}$ & $62(3977)$ & $67(58-100)$ & 0.315 \\
\hline Completed exercise sessions $[n]^{a}$ & $5(2-6.5)$ & $6(2-8)$ & 0.417 \\
\hline \multicolumn{4}{|l|}{ Reason for missed exercise sessions } \\
\hline Blood values [n] & 9 & 2 & 0.109 \\
\hline Well-being [n] & 17 & 9 & 0.475 \\
\hline Infection [n] & 1 & 4 & 0.536 \\
\hline Reduced vigilance $^{\mathrm{b}}[\mathrm{n}]$ & 13 & 7 & 1.000 \\
\hline Afraid of worsened side effects [n] & 1 & 3 & 0.887 \\
\hline Another appointment [n] & 0 & 1 & 0.669 \\
\hline Separate room for training was not available [n] & 1 & 0 & 0.740 \\
\hline
\end{tabular}

${ }^{a}$ Median (range), $n$ number of missed exercise sessions; ${ }^{b}$ patients were unresponsive

change in chemotherapy-induced side effects after training compared to pre-training, while 3 would represent a great increase). Additionally, 63\% of IG patients experienced WBV as "quite good", $30 \%$ as "very good", $7 \%$ as "marginally good" and $0 \%$ feedback "not good at all" (Fig. 2b). We observed no changes in either group in their blood pressure or heart rate values post-exercising compared to pre-exercising as well as post-intervention compared to pre-intervention (Table 3).

\section{Functional performance}

IG patients improved their jump height significantly $(2.3 \mathrm{~cm}, 95 \%$ CI 0.1-4.4, $p=0.028)$, while the CG's jump height was unchanged $(-3.3 \mathrm{~cm}, 95 \% \mathrm{CI}-13.0-3.6, p=$ 0.345). Power output ( $\left.\mathrm{P}_{\text {max_CMI }}\right)$ of both groups remained stable over time. No changes after intervention were observed either in any group (IG or CG) for the duration of CRT or in their power output during CRT $\left(\mathrm{P}_{\text {max } C R T}\right)$.

During balance tasks, only the IG's sway path in the semi-tandem stance conditions was augmented after intervention (EO: $60 \mathrm{~mm}, 95 \% \mathrm{CI} 2-236, p=0.046$; EC: $88 \mathrm{~mm}, 95 \%$ CI 49-214, $p=0.028)$. The monopedal stance revealed no changes. All the CG's balance performances were unchanged. Furthermore, our analysis of standard ellipse revealed no inter- or intra-group changes. All functional-performance results are illustrated in Table 4.

\section{Mobility}

IG patients reduced the time they needed to do the TUG test $(-1.3 \mathrm{~s}, 95 \% \mathrm{CI}-2.53--0.7, p=0.027)$, while the CG revealed no change $(-1.1 \mathrm{~s}, 95 \% \mathrm{CI}-6.4-1, p=0.138)$ (see Table 4).
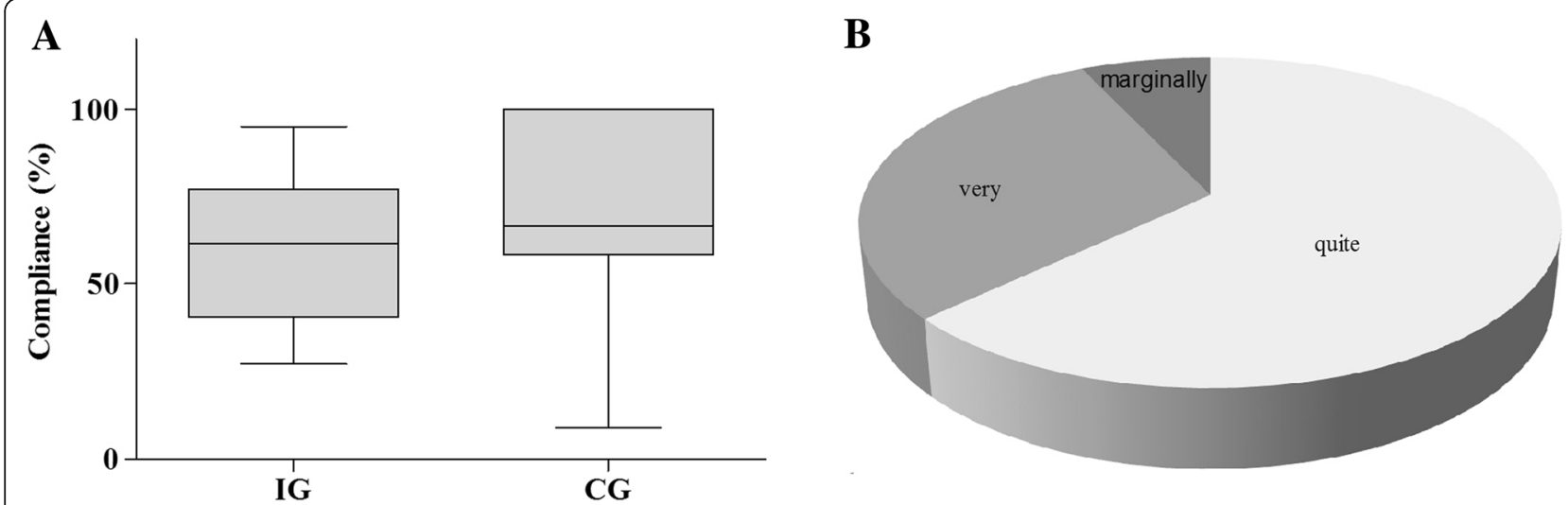

Fig. 2 Feasibility of WBV - Rate of training compliance and individual training perception. a Distribution of training compliance for IG and CG. Box-and-whisker plots showing the lower quartile (25th percentile), median (50th percentile), upper quartile (75th percentile) and degree of dispersion as $95 \%$ confidence interval $(95 \% \mathrm{Cl})$. b Percentage distribution of individual training's perception after WBV following the question "Did the exercise session do you any good?/Did the workout make you feel good?". Quite good 63.27\%, very good: 29.97\%, marginally good 6.66\%, not good at all 0\% 
Table 3 Changes in vital parameters and weight

\begin{tabular}{|c|c|c|c|c|c|c|c|}
\hline & & $n$ & $\mathrm{TO}^{\mathrm{a}}$ median (range) & $n$ & $\mathrm{~T} 1^{\mathrm{a}}$ median (range) & median difference $(95 \% \mathrm{Cl})$ & $P$ \\
\hline \multicolumn{8}{|l|}{ Blood pressure } \\
\hline \multirow[t]{3}{*}{ Systolic (mmHg) } & IG & 6 & $128(110-145)$ & 6 & $110(100-123)$ & $-20(-43-0)$ & 0.068 \\
\hline & $C G$ & 5 & $120(115-130)$ & 5 & $110(105-125)$ & $-8(-20-5)$ & 0.141 \\
\hline & $P$ & & 0.662 & & 0.537 & 0.662 & \\
\hline \multirow[t]{3}{*}{ Diastolic (mmHg) } & IG & 6 & $80(70-90)$ & 6 & $70(70-80)$ & $-8(-15-3)$ & 0.102 \\
\hline & $C G$ & 5 & $80(60-85)$ & 5 & $75(70-90)$ & $0(-5-15)$ & 0.705 \\
\hline & $P$ & & 0.662 & & 0.247 & 0.177 & \\
\hline \multirow[t]{3}{*}{ Heart rate (bpm) } & IG & 6 & $81(64-97)$ & 6 & $94(71-100)$ & $11(-11-22)$ & 0.345 \\
\hline & CG & 5 & $92(76-100)$ & 5 & $80(76-90)$ & $-5(-22-13)$ & 0.225 \\
\hline & $P$ & & 0.329 & & 0.537 & 0.177 & \\
\hline \multirow[t]{4}{*}{ Weight (kg) } & IG & 6 & $76(67-80.3)$ & 6 & $74.4(66-83.5)$ & $0.1(-2.5-3.2)$ & 0.917 \\
\hline & CG & 5 & $80(71.8-91)$ & 5 & $77(73-80)$ & $-2.2(-12-1.2)$ & 0.144 \\
\hline & $P$ & & 0.247 & & 0.662 & 0.247 & \\
\hline & & $n$ & Before exercise session ${ }^{a}$ median (range) & $n$ & After exercise session median (range) & median difference $(95 \% \mathrm{Cl})$ & $P$ \\
\hline \multicolumn{8}{|l|}{ Blood pressure } \\
\hline \multirow[t]{3}{*}{ Systolic (mmHg) } & IG & 6 & $118(112-137)$ & 6 & $118(113-135)$ & $0.5(-4-3)$ & 0.686 \\
\hline & CG & 5 & $114(112-127)$ & 5 & $119(111-136)$ & $4(-1-9)$ & 0.078 \\
\hline & $P$ & & 0.792 & & 1.000 & 0.082 & \\
\hline \multirow[t]{3}{*}{ Diastolic (mmHg) } & IG & 6 & $79(68-86)$ & 6 & $78(73-83)$ & $0(-3-5)$ & 0.893 \\
\hline & CG & 5 & $76(71-82)$ & 5 & $77(71-84)$ & $1(0-3)$ & 0.068 \\
\hline & P & & 0.792 & & 0.931 & 0.429 & \\
\hline
\end{tabular}

${ }^{a}$ Median (range); bpm beats per minute

\section{Discussion}

Aim of our prospective, randomized controlled pilot study was to prove for the first time the feasibility of WBV training for hospitalized cancer patients during intensive or high-dose chemotherapy. We did not observe any WBV-related adverse events, the groups' training compliance and reasons for missed exercise sessions were similar, and patients did not report any worsening of chemotherapy-related side effects after WBV sessions. Furthermore, as previously assumed, blood pressure was nearly unaffected by WBV. We thus succeeded in proving the feasibility of WBV in this setting and have justified its application in subsequent investigations evaluating its relative benefits. Additionally, we detected functional benefits due to WBV, indicated by their improved jumping- and TUG performance. Although our intervention did not lead to significant differences between groups over the intervention period, our results indicate that WBV may counteract some functional worsening during chemotherapy.

Due to the loss of physical capacity during treatment $[51,52]$ cancer patients are encouraged to be physically active to preserve their functional status $[12,14]$ and to reduce the risk of adverse health outcomes [11]. Aerobic exercise is well-researched, and it is safe and effective for cancer patients even during most intensive treatments
$[16,38]$. However, in light of muscle-mass loss and a considerable decline in functional performance [18], intensive and functional-oriented resistance exercises might counteract those impairments more effectively than aerobic exercises. In general, a patient's condition and potential therapy-related side effects like cytopenia i.e. thrombocytopenia will undoubtedly limit the intensity and volume of resistance training, especially in those undergoing intensive chemotherapy [14]. Thus, resistance training during chemotherapy usually consists of exercises with therabands and body weight in combination with aerobic exercises [19, 53, 54]. To date, there is only one randomized controlled study [21] investigating the effect of exclusively resistance training on cancer patients during chemotherapy. However, that study focused solely on the effects on protein metabolism and did not analyze functional performance [21]. Resistance training with high intensity and great neuromuscular impact would be most effective to counteract muscle mass loss during long periods of inactivity [55]. Indeed, this is associated with a rise in blood pressure $[56,57]$ that increases the risk of bleeding when patient's platelets are low. Furthermore, it usually requires that participants be willing to actively exhaust themselves in a state of physical discomfort. Thus, considering a patient's physical 
Table 4 Results of functional performance and mobility

\begin{tabular}{|c|c|c|c|c|c|c|c|}
\hline & & $n$ & T0 median (range) & $n$ & T1 median (range) & median difference ${ }^{\mathrm{a}}(95 \% \mathrm{Cl})$ & $P$ \\
\hline \multicolumn{8}{|l|}{ Functional performance } \\
\hline \multirow[t]{3}{*}{ Jumping height (cm) } & IG & 6 & $24.9(24.5-45.0)$ & 6 & $28.0(26.1-45.2)$ & $2.3(0.1-4.4)$ & $0.028^{*}$ \\
\hline & CG & 5 & $25.6(20.6-36.5)$ & 5 & $24.4(18.3-33.1)$ & $-3.3(-13.0-3.6)$ & 0.345 \\
\hline & $P$ & & 0.792 & & 0.329 & 0.126 & \\
\hline \multirow[t]{3}{*}{$P_{\max \_C M J}(W / k g)$} & IG & 6 & $26.3(23.5-44)$ & 6 & $25.3(25-45.3)$ & $-0.9(-3.9-1.4)$ & 0.345 \\
\hline & CG & 5 & $28.1(24.8-28.1)$ & 5 & $28.6(20.9-30.8)$ & $-0.6(-14.5-2.7)$ & 0.500 \\
\hline & $P$ & & 0.662 & & 0.792 & 1.00 & \\
\hline \multirow[t]{3}{*}{ Duration_CRT (sec) } & IG & 6 & $1.9(1.2-2.8)$ & 6 & $1.8(1.1-2.9)$ & $-0.0(-0.2-0.2)$ & 0.686 \\
\hline & CG & 5 & $2.5(1.9-3.4)$ & 5 & $2.5(1.5-3.7)$ & $-0.0(-0.6-0.6)$ & 0.686 \\
\hline & $P$ & & 0.247 & & 0.429 & 1.00 & \\
\hline \multirow[t]{3}{*}{$P_{\max \_C R T}(W / k g)$} & IG & 6 & $10.9(8.9-17.7)$ & 6 & $11.4(9.6-18.6)$ & $-0.1(-1.1-1.3)$ & 0.600 \\
\hline & CG & 5 & $12.4(8.1-14.2)$ & 5 & $10.9(6.8-16.4)$ & $0.1(-3.3-3.1)$ & 0.893 \\
\hline & $P$ & & 0.792 & & 0.792 & 1.00 & \\
\hline \multicolumn{8}{|l|}{ Balance performance } \\
\hline \multirow[t]{3}{*}{$\mathrm{ST}_{\mathrm{EO}}$ sway path (mm) } & IG & 6 & $549(447-591)$ & 6 & $579(457-713)$ & $60(2-236)$ & $0.046^{*}$ \\
\hline & CG & 5 & 498 (333-794) & 5 & $471(390-585)$ & $-47(-220-128)$ & 0.225 \\
\hline & $P$ & & 0.249 & & 0.247 & 0.082 & \\
\hline \multirow[t]{3}{*}{$\mathrm{ST}_{\mathrm{EO}}$ standard ellipse $\left(\mathrm{cm}^{2}\right)$} & IG & 6 & $3.6(1.6-8.0)$ & 6 & $4.4(2.8-6.8)$ & $0.9(-1.1-2.3)$ & 0.345 \\
\hline & $C G$ & 5 & $2.3(0.8-7.7)$ & 5 & $3.6(0.8-4.4)$ & $0.3(-1.5-2.9)$ & 0.893 \\
\hline & $P$ & & 0.249 & & 0.247 & 0.622 & \\
\hline \multirow[t]{3}{*}{$\mathrm{ST}_{\mathrm{EC}}$ sway path $(\mathrm{mm})$} & IG & 6 & $1117(656-1386)$ & 6 & 1203 (668-1503) & $88(49-214)$ & $0.028^{*}$ \\
\hline & CG & 5 & $888(13-2171)$ & 5 & 935 (655-1672) & $-142(-500-122)$ & 0.345 \\
\hline & $P$ & & 0.792 & & 0.429 & 0.126 & \\
\hline \multirow[t]{3}{*}{$\mathrm{ST}_{\mathrm{EC}}$ standard ellipse $\left(\mathrm{cm}^{2}\right)$} & IG & 6 & $9.9(3.2-12.2)$ & 6 & $9.4(2.5-11.3)$ & $0.5(-3.2-3.2)$ & 0.753 \\
\hline & $C G$ & 5 & $5.1(2.7-11.5)$ & 5 & $5.2(1.7-9.1)$ & $-0.9(-2.4-0.6)$ & 0.225 \\
\hline & $P$ & & 0.177 & & 0.126 & 0.931 & \\
\hline \multirow[t]{3}{*}{ MS EO sway path $(\mathrm{mm})$} & IG & 6 & $1621(1295-2350)$ & 4 & $1360(926-2462)$ & $-125(-482-176)$ & 0.465 \\
\hline & CG & 5 & $1394(1264-2111)$ & 5 & $1546(1254-1731)$ & $-53(-379-273)$ & 0.500 \\
\hline & $P$ & & 0.429 & & 0.556 & 1.00 & \\
\hline \multirow[t]{3}{*}{$\mathrm{MS}_{\mathrm{EO}}$ standard ellipse $\left(\mathrm{cm}^{2}\right)$} & IG & 6 & $8.0(6.6-16.9)$ & 4 & $5.3(3.6-8.1)$ & $-3.2(-11.6--0.6)$ & 0.068 \\
\hline & CG & 5 & $6.1(3.9-8.3)$ & 5 & $5.5(3.8-8.8)$ & $-0.1(-1.1-1.5)$ & 0.500 \\
\hline & $P$ & & 0.177 & & 0.730 & 0.063 & \\
\hline \multicolumn{8}{|l|}{ Mobility (TUG) } \\
\hline \multirow[t]{3}{*}{ Duration (sec) } & IG & 6 & $6.2(3.7-10)$ & 6 & $5(2.9-7.7)$ & $-1.3(-2.5--0.7)$ & $0.027^{*}$ \\
\hline & CG & 5 & $5.9(4.5-17)$ & 5 & $5.5(4.8-10.6)$ & $-1.1(-6.4-1)$ & 0.138 \\
\hline & $P$ & & 0.662 & & 0.329 & 1.00 & \\
\hline
\end{tabular}

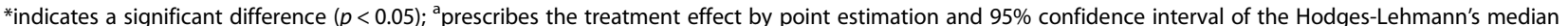
differences for paired groups; $S T_{E O}$ semi-tandem stance with eyes open, $S T_{E C}$ semi-tandem stance with eyes closed, $M S_{E O}$ monopedal stance with eyes open, $M S_{E C}$ monopedal stance with eyes closed, TUG timed-up-and-go test

and mental condition in line with current guidelines [14, 40], high intensity resistance training during intensive chemotherapy is not feasible. On the other hand, WBV is a strengthening exercise method known to increase muscle power output even under passive training conditions by inducing a tonic-vibration reflex addressing many muscle fibers simultaneously [26, 29]. Additional exercises like the static and dynamic squats our patients also performed can further intensify muscular activity [58]. Furthermore, WBV-induced periodic dynamic movements cause increased blood flow, potentially inhibiting a rise in blood pressure [33]. Thus, WBV has less impact on vital 
signs [59, 60]. Since we documented blood pressure immediately before and after each WBV-exercise session, our results are in line with research findings indicating that WBV does not lead to a considerable increase in blood pressure. We therefore assume that WBV is a convenient and low-threshold exercise method for patients undergoing intensive chemotherapy and unable to perform exercises of high intensity and long duration. Accordingly, we are the first to have confirmed its feasibility despite chemotherapy-related side effects in this study. Patients were capable of performing the prescribed exercises during the 20-min WBV sessions, and none reported a worsening of physical well-being after their WBV session or complained of being overloaded by our program. Consequently, we observed good training compliance.

What is clinically relevant: WBV training positively influenced functional performance. In line with other working groups who observed improved strength capacity $[61,62]$ or improved jump height $[44,63]$ after WBV especially in weak or untrained persons, we detected enhanced jumping and TUG performance in our IG after the intervention. Jumping performance is influenced by various factors: the rate of force development, which in turn is affected by the stretch-shortening cycle's efficacy $[64,65]$ and the level of reactive strength so essential for common daily situations such as adequate reactions to unexpected perturbations [66, 67]. WBV induces frequency-dependent, repeated muscle contractions culminating in a tonic vibration reflex that enhances the recruitment of motor units $[26,27]$ and that may improve the stretch-shortening cycle and inter- and intramuscular coordination. Reactive strength is more likely to depend on neuromuscular processes than on muscle size [68] and thus represents a clear functional gain. For example, reactive strength is an influencing variable of walking speed, one acknowledged predictor of mortality [9, 69, 70]. Consequently, enhanced jumping performance means improved interaction of muscles, tendons, and the neuromuscular system and therefore better functioning of the locomotoric system. The functional gains due to WBV are also visible in the improved performance on the TUG test. TUG is a common clinical test to evaluate patients' mobility [71]. The time needed to complete this task strongly correlates with the independence during daily activities [46]. Thus, enhancing this ability is a crucial factor for a patient's autonomy. CRT performance, also a common clinical test for daily activity function and lower body strength [71], remained stable on a level comparable to age-adjusted reference values [40,46]. Taking into account that the IG and CG carried out five respectively six exercise sessions during 27 days of hospitalization, we assume that the amount and intensity of WBV exercise sessions were insufficient to significantly affect lower-body strength. But we believe that our WBV intervention could enhance neuromuscular interaction and inter- and intramuscular coordination, in line with findings of Perchthaler et al. (2015) [72]. In general, inter- and intramuscular coordination is enhanced prior to considerable increases in strength [73, 74]. Accordingly, we presume that a longer intervention period with consequently more exercise sessions would also reveal group effects over time. Moreover, we propose evaluating muscle strength and function in greater detail to confirm our preliminary findings. Overall, preserving or even improving functional performance should be of particular interest when exercising with cancer patients receiving medical treatment, because there is ample evidence that functional impairments are highly relevant prognostic factors for survival [11]. Factors such as long periods of inactivity $[6,31,75]$, neurotoxic agents among chemotherapy [76] or aging itself [45] lead to difficulty connecting sensory information and motor action [77]. This often results in impaired postural control and balance performance - determinants of functional status and significant risk factors for falls $[78,79]$. We speculated that the repetitive stimuli of external perturbation induced by WBV would positively affect posture stability $[62,80]$. In this context, Streckmann et al. (2018) [37] are even investigating WBV's preventive effect on neuropathic symptoms, including postural stability, in patients undergoing neurotoxic chemotherapy. However, against our expectations, our balance-control analysis revealed that WBV was not superior to aerobic exercise. During the semi-tandem stance after intervention, IG's sway path was even augmented. According to two reviews, WBV's effects on balance performance remain inconsistent [81, 82]. Muehlbauer et al. [83] defined balance control and lower-extremity strength as independent neuromuscular systems that should be exercised separately. In conclusion, we propose that specific balance exercises be included that may prevent or even reduce balance impairments during hospitalization and thus further lower the risk of adverse health events [84]. Considering the non-significant post-intervention group effects, we cannot explicitly assume WBV's superiority to aerobic exercises. However, the functional improvements we observed exclusively in our IG support the hypothesis that WBV has greater influence on neuromuscular adaptions than aerobic cycling.

\section{Conclusion}

To best of our knowledge, our prospective, randomized controlled pilot study is the first study proving the feasibility of WBV immediate during intensive or high-dose chemotherapy in hospitalized cancer patients. Our results also suggest that WBV can improve mobility and jumping height in these patients. Such factors might be associated with greater autonomy and even better survival prognosis. 
We thus recommend implementing WBV as an alternative training method to aerobic exercise training during intensive chemotherapy to maintain patients' functional status. However, the specific advantages and relative benefits compared to other forms of resistance training require further investigation in greater detail and with larger sample sizes. The success we have had in our pilot study paves the way for further WBV-based investigations during chemotherapy.

\section{Abbreviations}

CG: Control group; Cl: Confidence interval; CMJ: Counter movement jump; COF: Center of force; CRT: Chair rising test; EC: Eyes closed; EO: Eyes open; IG: Intervention group; TUG: Timed-up-and-go; WBV: Whole body vibration

\section{Acknowledgements}

We thank the staff of the Holthusen ward for their collaboration, and all patients for their participation. Furthermore we thank Elisa Straub for supporting us for exercise sessions and assessments.

The article processing charge was funded by the German Research Foundation (DFG) and the Albert Ludwigs University Freiburg in the funding program Open Access Publishing.

\section{Availability of data and materials}

This article only includes summarized data of this study. Raw data is available from the corresponding author upon reasonable request.

\section{Authors' contributions}

AP recruited patients, collected data, did the data analysis and interpretation of the data and drafted the manuscript. AW and SK designed the study, supervised the measurement and provided assistance for the data analysis and interpretation as well as drafting of the manuscript. AG and HB participated in the design of the study and revised the manuscript. HB did the medical clarification for patients' study participation. All authors made contributions to the paper, are in agreement with the content and read the final manuscript.

\section{Ethics approval and consent to participate}

Ethics approval was given by the Ethics Committee of the University of Freiburg (267/12). Every patient had to sign written informed consent prior to inclusion.

\section{Consent for publication}

Not applicable.

\section{Competing interests}

The authors have no competing interests to declare.

\section{Publisher's Note}

Springer Nature remains neutral with regard to jurisdictional claims in published maps and institutional affiliations.

\section{Author details \\ ${ }^{1}$ Department of Medicine I (Specialties: Hematology, Oncology, and Stem-Cell Transplantation), Faculty of Medicine, Medical Center - University of Freiburg, Hugstetterstr. 55, 79106 Freiburg, Germany. ${ }^{2}$ Institute for Exercise- and Occupational Medicine, Faculty of Medicine, Medical Center - University of Freiburg, Freiburg, Germany. ${ }^{3}$ Department of Sport and Sport Science, University of Freiburg, Freiburg, Germany.}

Received: 29 January 2018 Accepted: 12 September 2018 Published online: 25 September 2018

\section{References}

1. de Lima M, Anagnostopoulos A, Munsell M, Shahjahan M, Ueno N, Ippoliti $C$, et al. Nonablative versus reduced-intensity conditioning regimens in the treatment of acute myeloid leukemia and high-risk myelodysplastic syndrome: dose is relevant for long-term disease control after allogeneic hematopoietic stem cell transplantation. Blood. 2004;104:865-72.

2. Erba HP. Prognostic factors in elderly patients with AML and the implications for treatment. Hematol Am Soc Hematol Educ Program. 2007;1: 420-8.

3. Reich G, Mapara MY, Reichardt P, Dörken B, Maschmeyer G. Infectious complications after high-dose chemotherapy and autologous stem cell transplantation: comparison between patients with lymphoma or multiple myeloma and patients with solid tumors. Bone Marrow Transplant. 2001;27:525-9.

4. Ewesuedo RB, Ratain MJ. Principles of Cancer chemotherapy. In: Vokes EE, Golomb HM, editors. Oncologic therapies. Berlin: Springer Berlin Heidelberg; 2003. p. 19-66. https://doi.org/10.1007/978-3-642-55780-4_3.

5. Buehring B, Belavý DL, Michaelis I, Gast U, Felsenberg D, Rittweger J. Changes in lower extremity muscle function after 56 days of bed rest. J Appl Physiol. 2011;111:87-94.

6. Rittweger J, Frost $\mathrm{H}$, Schiess $\mathrm{H}$, Ohshima H, Alkner B, Tesch $\mathrm{P}$, et al. Muscle atrophy and bone loss after 90 days' bed rest and the effects of flywheel resistive exercise and pamidronate: results from the LTBR study. Bone. 2005; 36:1019-29.

7. Rejeski WJ, King AC, Katula JA, Kritchevsky S, Miller ME, Walkup MP, et al. Physical activity in prefrail older adults: confidence and satisfaction related to physical function. J Gerontol B Psychol Sci Soc Sci. 2008;63:P19-26.

8. Garber CE, Blissmer B, Deschenes MR, Franklin BA, Lamonte MJ, Lee I-M, et al. Quantity and quality of exercise for developing and maintaining cardiorespiratory, musculoskeletal, and Neuromotor fitness in apparently healthy adults: guidance for prescribing exercise. Med Sci Sports Exerc. 2011:43:1334-59.

9. Cesari M, Kritchevsky SB, Newman AB, Simonsick EM, Harris TB, Penninx BW, et al. Added value of physical performance measures in predicting adverse health-related events: results from the health, aging and body composition study. J Am Geriatr Soc. 2009;57:251-9.

10. Urbain P, Birlinger J, Lambert C, Finke J, Bertz H, Biesalski H-K. Longitudinal follow-up of nutritional status and its influencing factors in adults undergoing allogeneic hematopoietic cell transplantation. Bone Marrow Transplant. 2013:48:446-51.

11. Brown JC, Harhay MO, Harhay MN. Physical function as a prognostic biomarker among cancer survivors. Br J Cancer. 2015;112:194-8.

12. Courneya KS, Friedenreich CM. Physical activity and cancer. Berlin: Springer; 2011

13. Brown JC, Winters-Stone K, Lee A, Schmitz KH. Cancer, physical activity, and exercise. Compr Physiol. 2012;2:2775-809.

14. Schmitz KH, Courneya KS, Matthews C, Demark-Wahnefried W, DA GO, Pinto BM, et al. American College of Sports Medicine Roundtable on Exercise Guidelines for Cancer Survivors. Med Sci Sports Exerc. 2010;42:1409-26.

15. Chang $P-H$, Lai $Y-H$, Shun $S-C$, Lin $L-Y$, Chen $M-L$, Yang $Y$, et al. Effects of a walking intervention on fatigue-related experiences of hospitalized acute myelogenous leukemia patients undergoing chemotherapy: a randomized controlled trial. J Pain Symptom Manag. 2008:35:524-34.

16. Dimeo F, Fetscher S, Lange W, Mertelsmann R, Keul J. Effects of aerobic exercise on the physical performance and incidence of treatment-related complications after high-dose chemotherapy. Blood. 1997;90:3390-4.

17. Coleman EA, Coon SK, Kennedy RL, Lockhart KD, Stewart CB, Anaissie EJ, et al. Effects of exercise in combination with epoetin alfa during high-dose chemotherapy and autologous peripheral blood stem cell transplantation for multiple myeloma. Oncol Nurs Forum. 2008;35:E53-61.

18. Baumann FT, Zopf EM, Nykamp E, Kraut L, Schüle K, Elter T, et al. Physical activity for patients undergoing an allogeneic hematopoietic stem cell transplantation: benefits of a moderate exercise intervention. Eur J Haematol. 2011;87:148-56.

19. Wiskemann J, Dreger $P$, Schwerdtfeger R, Bondong A, Huber G, Kleindienst $\mathrm{N}$, et al. Effects of a partly self-administered exercise program before, during, and after allogeneic stem cell transplantation. Blood. 2011;117:2604-13.

20. Mello M, Tanaka C, Dulley FL. Effects of an exercise program on muscle performance in patients undergoing allogeneic bone marrow transplantation. Bone Marrow Transplant. 2003:32:723-8.

21. Cunningham BA, Morris $G$, Cheney CL, Buergel N, Aker SN, Lenssen P. Effects of resistive exercise on skeletal muscle in marrow transplant recipients receiving total parenteral nutrition. JPEN J Parenter Enteral Nutr. 1986;10:558-63.

22. Morley JE, Thomas DR, Wilson M-MG. Cachexia: pathophysiology and clinical relevance. Am J Clin Nutr. 2006;83:735-43. 
23. Schakman O, Kalista S, Barbé C, Loumaye A, Thissen JP. Glucocorticoidinduced skeletal muscle atrophy. Int J Biochem Cell Biol. 2013;45:2163-72.

24. Kyle UG, Chalandon Y, Miralbell R, Karsegard VL, Hans D, Trombetti A, et al. Longitudinal follow-up of body composition in hematopoietic stem cell transplant patients. Bone Marrow Transplant. 2005;35:1171-7.

25. Hayes SC, Spence RR, Galvão DA, Newton RU. Australian Association for Exercise and Sport Science position stand: optimising cancer outcomes through exercise. J Sci Med Sport Sports Med Aust. 2009;12:428-34.

26. Rittweger J. Vibration as an exercise modality: how it may work, and what its potential might be. Eur J Appl Physiol. 2010;108:877-904

27. Zaidell LN, Mileva KN, Sumners DP, Bowtell JL. Experimental evidence of the tonic vibration reflex during whole-body vibration of the loaded and unloaded leg. PLoS One. 2013;8:e85247.

28. Marín PJ, Santos-Lozano A, Santin-Medeiros F, Delecluse C, Garatachea N. A comparison of training intensity between whole-body vibration and conventional squat exercise. J Electromyogr Kinesiol. 2011;21:616-21.

29. Delecluse C, Roelants M, Verschueren S. Strength increase after whole-body vibration compared with resistance training. Med Sci Sports Exerc. 2003;35 http://journals.lww.com/acsm-msse/Fulltext/2003/06000/Strength_Increase_ after_Whole_Body_Vibration.21.aspx.

30. Runge $M$, Rehfeld $G$, Resnicek E. Balance training and exercise in geriatric patients. J Musculoskelet Neuronal Interact. 2000;1:61-5.

31. Belavý DL, Miokovic T, Armbrecht G, Rittweger J, Felsenberg D. Resistive vibration exercise reduces lower limb muscle atrophy during 56-day bedrest. J Musculoskelet Neuronal Interact. 2009;9:225-35.

32. Hazell TJ, Thomas GWR, DeGuire JR, Lemon PWR. Vertical whole-body vibration does not increase cardiovascular stress to static semi-squat exercise. Eur J Appl Physiol. 2008;104:903-8.

33. Lythgo N, Eser P, De Groot P, Galea M. Whole-body vibration dosage alters leg blood flow. Clin Physiol Funct Imaging. 2009;29:53-9.

34. Schönsteiner SS, Bauder Mißbach H, Benner A, Mack S, Hamel T, Orth M, et al. A randomized exploratory phase 2 study in patients with chemotherapy-related peripheral neuropathy evaluating whole-body vibration training as adjunct to an integrated program including massage, passive mobilization and physical exercises. Exp Hematol Oncol. 2017;6:5.

35. Van Ruymbeke B, Boone J, Coorevits P, Vanderstraeten G, Bourgois J. Whole-body vibration in breast cancer survivors: a pilot study exploring its effects on muscle activity and subjectively perceived exertion. Int J Rehabil Res. 2014;37:371-4.

36. Salhi B, Haenebalcke C, Perez-Bogerd S, Nguyen MD, Ninane V, Malfait TLA, et al. Rehabilitation in patients with radically treated respiratory cancer: a randomised controlled trial comparing two training modalities. Lung Cancer Amst Neth. 2015:89:167-74.

37. Streckmann F, Balke M, Lehmann HC, Rustler V, Koliamitra C, Elter T, et al. The preventive effect of sensorimotor- and vibration exercises on the onset of Oxaliplatin- or vinca-alkaloid induced peripheral neuropathies - STOP. BMC Cancer. 2018;18. https://doi.org/10.1186/ s12885-017-3866-4.

38. Liu RDKS, Chinapaw MJM, Huijgens PC, van Mechelen W. Physical exercise interventions in haematological cancer patients, feasible to conduct but effectiveness to be established: a systematic literature review. Cancer Treat Rev. 2009;35:185-92

39. Álvarez-Barbosa F, del Pozo-Cruz J, del Pozo-Cruz B, Alfonso-Rosa RM, Rogers ME, Zhang Y. Effects of supervised whole body vibration exercise on fall risk factors, functional dependence and health-related quality of life in nursing home residents aged 80+. Maturitas. 2014;79:456-63.

40. Scharhag-Rosenberger F, Becker T, Streckmann F, Schmidt K, Berling A, Bernardi A, et al. Studien zu körperlichem Training bei onkologischen Patienten: Empfehlungen zu den Erhebungsmethoden. Dtsch Z Für Sportmed. 2014;65:304-13.

41. Pescatello LS. American College of Sports Medicine, editors. ACSM's guidelines for exercise testing and prescription. 9th ed. Philadelphia: Wolters Kluwer/Lippincott Williams \& Wilkins Health; 2014

42. Borg G. Psychophysical bases of perceived exertion. Med Sci Sports Exerc. 1982;14:377-81.

43. Ritzmann R, Gollhofer A, Kramer A. The influence of vibration type, frequency, body position and additional load on the neuromuscular activity during whole body vibration. Eur J Appl Physiol. 2013;113:1-11.

44. Colson SS, Petit P-D. Lower limbs power and stiffness after whole-body vibration. Int J Sports Med. 2013;34:318-23.

45. Vandervoort AA. Aging of the human neuromuscular system. Muscle Nerve. 2002;25:17-25
46. Guralnik JM, Simonsick EM, Ferrucci L, Glynn RJ, Berkman LF, Blazer DG, et al. A short physical performance battery assessing lower extremity function: association with self-reported disability and prediction of mortality and nursing home admission. J Gerontol. 1994;49:M85-94.

47. Zech A, Hübscher M, Vogt L, Banzer W, Hänsel F, Pfeifer K. Balance training for neuromuscular control and performance enhancement: a systematic review. J Athl Train. 2010;45:392-403.

48. Taube W, Gruber M, Gollhofer A. Spinal and supraspinal adaptations associated with balance training and their functional relevance. Acta Physiol Oxf Engl. 2008;193:101-16.

49. Podsiadlo D, Richardson S. The timed "up \& go": a test of basic functional mobility for frail elderly persons. J Am Geriatr Soc. 1991;39:142-8.

50. Bennell K, Dobson F, Hinman R. Measures of physical performance assessments: self-paced walk test (SPWT), stair climb test (SCT), sixminute walk test (6MWT), chair stand test (CST), timed up \& go (TUG), sock test, lift and carry test (LCT), and Car task. Arthritis Care Res. 2011; 63 Suppl 11:\$350-70

51. Christensen JF, Jones LW, Andersen JL, Daugaard G, Rorth M, Hojman P. Muscle dysfunction in cancer patients. Ann Oncol. 2014;25:947-58.

52. Coackley A, Hutchinson T, Saltmarsh P, Kelly A, Ellershaw J, Marshall E, et al. Assessment and management of fatique in patients with advanced cancer: developing guidelines. Int J Palliat Nurs. 2002;8:381-8.

53. Oechsle K, Aslan Z, Suesse $Y$, Jensen W, Bokemeyer C, de Wit M. Multimodal exercise training during myeloablative chemotherapy: a prospective randomized pilot trial. Support Care Cancer. 2014;22:63-9.

54. Jarden M, Baadsgaard MT, Hovgaard DJ, Boesen E, Adamsen L. A randomized trial on the effect of a multimodal intervention on physical capacity, functional performance and quality of life in adult patients undergoing allogeneic SCT. Bone Marrow Transplant. 2009;43:725-37.

55. Hackney KJ, Downs ME, Ploutz-Snyder L. Blood flow restricted exercise compared to high load resistance exercise during unloading. Aerosp Med Hum Perform. 2016;87:688-96.

56. Libardi C, Catai A, Miquelini M, Borghi-Silva A, Minatel V, Alvarez I, et al. Hemodynamic responses to blood flow restriction and resistance exercise to muscular failure. Int J Sports Med. 2016;38:134-40.

57. Miyachi M, Kawano H, Sugawara J, Takahashi K, Hayashi K, Yamazaki K, et al. Unfavorable effects of resistance training on central arterial compliance: a randomized intervention study. Circulation. 2004;110:2858-63.

58. Abercromby AFJ, Amonette WE, Layne CS, McFarlin BK, Hinman MR, Paloski WH. Vibration exposure and biodynamic responses during whole-body vibration training. Med Sci Sports Exerc. 2007;39:1794-800.

59. Wong A, Alvarez-Alvarado S, Kinsey AW, Figueroa A. Whole-body vibration exercise therapy improves cardiac autonomic function and blood pressure in obese pre- and stage 1 hypertensive postmenopausal women. J Altern Complement Med N Y N. 2016:22:970-6.

60. ueroa A, Gil R, Sanchez-Gonzalez MA. Whole-body vibration attenuates the increase in leg arterial stiffness and aortic systolic blood pressure during post-exercise muscle ischemia. Eur J Appl Physiol. 2011;111:1261-8.

61. Lachance C, Weir P, Kenno K, Horton S. Is whole-body vibration beneficial for seniors? Eur Rev Aging Phys Act. 2012;9:51-62.

62. Zhang L, Weng C, Liu M, Wang Q, Liu L, He Y. Effect of whole-body vibration exercise on mobility, balance ability and general health status in frail elderly patients: a pilot randomized controlled trial. Clin Rehabil. 2014;28:59-68.

63. Cochrane DJ, Stannard SR. Acute whole body vibration training increases vertical jump and flexibility performance in elite female field hockey players. Br J Sports Med. 2005;39:860-5.

64. Kopper B, Csende Z, Trzaskoma L, Tihanyi J. Stretch-shortening cycle characteristics during vertical jumps carried out with small and large range of motion. J Electromyogr Kinesiol. 2014;24:233-9.

65. Gollhofer A, Strojnik V, Rapp W, Schweizer L. Behaviour of triceps surae muscle-tendon complex in different jump conditions. Eur J Appl Physiol. 1992;64:283-91

66. Brauer SG, Neros C, Woollacott M. Balance control in the elderly: do masters athletes show more efficient balance responses than healthy older adults? Aging Clin Exp Res. 2008:20:406-11.

67. Boelens C, Hekman EEG, Verkerke GJ. Risk factors for falls of older citizens. Technol Health Care. 2013:21:521-33.

68. Rubio-Arias JÁ, Ramos-Campo DJ, Esteban P, Martínez F, Jiménez JF. Effect of 6-weeks WBVT on the behaviour of the lower limb muscle fibres during vertical jumping. J Sports Sci. 2017;36:1-9. 
69. Onder G, Penninx BWJH, Ferrucci L, Fried LP, Guralnik JM, Pahor M. Measures of physical performance and risk for progressive and catastrophic disability: results from the Women's health and aging study. J Gerontol A Biol Sci Med Sci. 2005;60:74-9.

70. Klepin HD, Geiger AM, Tooze JA, Newman AB, Colbert LH, Bauer DC, et al. Physical performance and subsequent disability and survival in older adults with malignancy: results from the health, aging and body composition study. J Am Geriatr Soc. 2010;58:76-82.

71. Jones CJ, Rikli RE, Beam WC. A 30-s chair-stand test as a measure of lower body strength in community-residing older adults. Res Q Exerc Sport. 1999;70:113-9.

72. Perchthaler D, Grau S, Hein T. Evaluation of a six-week whole-body vibration intervention on neuromuscular performance in older adults. J Strength Cond Res. 2015;29:86-95.

73. Häkkinen K, Komi PV. Electromyographic changes during strength training and detraining. Med Sci Sports Exerc. 1983;15:455-60.

74. Rutherford OM, Jones DA. The role of learning and coordination in strength training. Eur J Appl Physiol. 1986;55:100-5.

75. Muir J, Judex S, Qin Y-X, Rubin C. Postural instability caused by extended bed rest is alleviated by brief daily exposure to low magnitude mechanical signals. Gait Posture. 2011;33:429-35.

76. Winters-Stone KM, Horak F, Jacobs PG, Trubowitz P, Dieckmann NF, Stoyles $S$, et al. Falls, functioning, and disability among women with persistent symptoms of chemotherapy-induced peripheral neuropathy. J Clin Oncol. 2017;35:2604-12.

77. Prioli AC, Freitas Júnior PB, Barela JA. Physical activity and postural control in the elderly: coupling between visual information and body sway. Gerontology. 2005;51:145-8.

78. Ward RE, Leveille SG, Beauchamp MK, Travison T, Alexander N, Jette AM, et al. Functional performance as a predictor of injurious falls in older adults. J Am Geriatr Soc. 2015;63:315-20.

79. Tinetti ME, Speechley M, Ginter SF. Risk factors for falls among elderly persons living in the community. N Engl J Med. 1988;319:1701-7.

80. Bogaerts A, Verschueren S, Delecluse C, Claessens AL, Boonen S. Effects of whole body vibration training on postural control in older individuals: a 1 year randomized controlled trial. Gait Posture. 2007;26:309-16.

81. Lam FMH, Lau RWK, Chung RCK, Pang MYC. The effect of whole body vibration on balance, mobility and falls in older adults: a systematic review and meta-analysis. Maturitas. 2012;72:206-13.

82. Orr R. The effect of whole body vibration exposure on balance and functional mobility in older adults: a systematic review and meta-analysis. Maturitas. 2015:80:342-58.

83. Muehlbauer T, Gollhofer A, Granacher U. Associations between measures of balance and lower-extremity muscle strength/power in healthy individuals across the lifespan: a systematic review and meta-analysis. Sports Med Auckl NZ. 2015:45:1671-92.

84. Rubenstein LZ. Falls in older people: epidemiology, risk factors and strategies for prevention. Age Ageing. 2006;35(Suppl 2):ii37-41.

Ready to submit your research? Choose BMC and benefit from:

- fast, convenient online submission

- thorough peer review by experienced researchers in your field

- rapid publication on acceptance

- support for research data, including large and complex data types

- gold Open Access which fosters wider collaboration and increased citations

- maximum visibility for your research: over $100 \mathrm{M}$ website views per year

At $\mathrm{BMC}$, research is always in progress.

Learn more biomedcentral.com/submissions 